\title{
Influence of ultrasonic activation in association with different final irrigants on intracanal smear layer removal
}

\author{
Matheus Albino Souza', Felipe Trentin Motter', Tobias Pitton Fontana', Marlos Barbosa Ribeiro², \\ Daniela Cristina Miyagaki', Doglas Cecchin ${ }^{1}$
}

\author{
${ }^{1}$ Universidade de Passo Fundo - UPF, School of Dentistry, Department of Restorative Dentistry, Passo Fundo, RS, Brazil \\ ${ }^{2}$ Universidade de Campinas - UNICAMP, Piracicaba Dental School, Department of Restorative Dentistry, Piracicaba, SP, Brazil
}

Received for publication: March 29, 2016 Accepted: May 16, 2016

Correspondence to: Matheus Albino Souza.

Programa de Pós-Graduação - Universidade de Passo Fundo

BR 285, São José, Prédio A7, Sala 2 CEP: 99052-900. Passo Fundo - RS-Brazil

Phone: +55 54 3316-8402

E-mail: matheus292@yahoo.com.br

\section{Abstract}

Aim: To evaluate the influence of ultrasonic activation (US) with different irrigant regimens in smear layer removal. Methods: One hundred bovine incisors were instrumented and divided into ten groups $(n=10)$ according to final irrigation protocols: distilled water (DW); DW+US; 17\% EDTA; QMix; 10\% citric acid; $37 \%$ phosphoric acid; 17\% EDTA+US; QMix+US; 10\% citric acid+US; 37\% phosphoric acid+US. The samples were then submitted to scanning electron microscopy where a score system was used to evaluate the images and effectiveness of proposed treatments. The data were statistically analyzed by Kruskal-Wallis and Mann-Whitney $U$ tests for intergroup comparisons as well as the Wilcoxon and Friedman tests for intragroup comparisons at $5 \%$ significance level. Results: In the cervical third, groups 17\% EDTA, QMix, 10\% citric acid, 17\% EDTA+US, QMix+US and $10 \%$ citric acid+US were more effective in smear layer removal ( $p<0.05)$; in the middle third, groups $17 \%$ EDTA+US and QMix+US were more effective in smear layer removal $(p<0.05)$; in the apical third, groups 17\% EDTA,17\% EDTA+US and QMix+US were more effective in smear layer removal $(p<0.05)$. Conclusions: US can aid 17\% EDTA and QMix in smear layer removal at the middle third and QMix at the apical third, contributing to the cleaning of root canal system.

Keywords: Root Canal Irrigants. Smear Layer. Ultrasonics.

\section{Introduction}

Microorganisms and their products are the main etiological factor of pulp and periapical pathology. They play a significant role in the induction and progression of the disease ${ }^{1}$. Therefore, chemomechanical procedures are necessary to control microbial agents, where the chemical action of auxiliary chemical substances and mechanical action of endodontic instruments contribute to adequate cleanliness during the root canal therapy.

However, an agglomeration of dentin chips, irrigant solutions, microorganisms and organic matter, called smear layer, forms during root canal preparation and remains adhered to the root canal walls ${ }^{2}$. The presence of smear layer represents a barrier to intracanal dentin that limits penetration of auxiliary chemical substances and intracanal dressings into infected dentinal tubules ${ }^{3}$. Furthermore, it also increases microleakage through usual root canal sealers and decreases the bond strength of resin-based materials ${ }^{4}$.

Several substances have been used in root canal therapy in order to promote smear layer removal, like EDTA, citric acid and phosphoric acid ${ }^{5}$. More recently, a novel endodontic irrigant called QMix (Dentsply Tulsa Dental Specialties, Tulsa, OK, USA), 
which contains EDTA, chlorhexidine and surfactant agent in its composition, have also been used as a final irrigation protocol in endodontics ${ }^{6}$. However, due to the anatomical complexity of the root canal system, inorganic and organic components cannot always be reached by irrigants ${ }^{7}$, requiring the use of auxiliary techniques to promote an effective smear layer removal.

The ultrasonic activation (US) is the activation of an endodontic instrument by an ultrasonic device placed inside the root canal. This promotes mechanical agitation of a chemical substance without instrument contact with the root canal wall ${ }^{8}$. Some studies have recommended the use of US to improve smear layer removal upon delivery of EDTA with needles without agitation $^{9,10}$. Despite the relevant studies concerning the benefits of this technique and EDTA on smear layer removal, there is no consensus in the literature regarding the use of US with other agents, such as QMix, citric acid and phosphoric acid. It limits the ability to make valid comparisons between the products, especially when considering the use of US.

Thus, the purpose of present study was to evaluate, in vitro, the influence of US with different final irrigants in intracanal smear layer removal, using scanning electron microscopy (SEM). The tested null hypothesis was that the use of US with four tested irrigants would not promote better removal of the smear layer.

\section{Material and methods}

This study was approved by the Ethics Committee of the School of Dentistry of University of Passo Fundo (Passo Fundo, RS, Brazil), protocol 016/2014.

\section{Smear Layer Production and Irrigation Protocols}

One hundred bovine incisors from animals killed for commercial reasons were used. The teeth were extracted from the jaws immediately after the death of the animals and stored in vials containing 4\% formalin (Royal Plás, Curitiba, PR, Brazil), in order to preserve their properties, for a period up to $72 \mathrm{~h}$. Dental crowns were sectioned with a rotating diamond saw $(\# 911 \mathrm{H}$ - Brasseler, Savannah, GA, USA) set at 20,000 rpm under water-coolant, so that all of the roots were $15 \mathrm{~mm}$ long.

All samples were prepared using the same protocol in order to remove pulp tissue, standardize the canal diameter and produce smear layer. The cervical third was prepared using \#4 and \#5 Largo drills (Dentsply-Maillefer, Ballaigues, Switzerland). The working length was established by introducing a \#10 K-file (Dentsply-Maillefer) in the canal until its tip was visualised at the apical foramen. One millimeter was subtracted from this measurement, establishing the working length. After that, only straight roots with apical diameters equal to the K-file size 25 (Dentsply-Maillefer) were included in this study. The roots were enlarged up to instrument \#60 (Dentsply-Maillefer), by serial instrumentation, using $2.5 \%$ sodium hypochlorite $(\mathrm{NaOCl})$ (Decloquimis, São Paulo, SP, Brazil) as irrigant, in order to remove organic components from dentin. The samples were completely filled with $2.5 \% \mathrm{NaOCl}$ and the root canals were irrigated with 2 $\mathrm{mL}$ of the same solution using disposable $5 \mathrm{~mL}$ syringes (Ultradent Products, South Jordan, UT, USA) and a 30-gauge needle (Navi
Tip, Ultradent Products) after each change of instrument. After complete root canal instrumentation, the teeth were irrigated with $5 \mathrm{~mL}$ of $\mathrm{NaOCl}$ (Decloquimis). Following preparation, each root was fixed with Putty-C Silicone for Impression (Silon2APS Dentsply, Petrópolis, RJ, Brazil) in a plastic micro-tube (Axygen Inc., Union City, CA, USA), to prevent the flow of chelating agents through the apical foramen.

The tested substances were 17\% EDTA (Biodinâmica, Ibiporã, PR, Brazil), QMix (Dentsply Tulsa Dental Specialties, Tulsa, OK, USA), 10\% citric acid (Biodinâmica) and 37\% phosphoric acid solution (Biodinâmica). The samples were randomly divided into 10 groups $(n=10)$ according to the protocol of final irrigation, as follows: distilled water (DW),control group; DW + US; 17\% EDTA; QMix; 10\% citric acid; 37\% phosphoric acid; $17 \%$ EDTA + US; QMix + US; $10 \%$ citric acid + US; $37 \%$ phosphoric acid + US.

The groups with no US were treated using the same protocol. First, the root canals were completely filled with $2 \mathrm{~mL}$ of the tested solution. Then, the tested solution remained in contact with root canal walls for $3 \mathrm{~min}$. After that, irrigation with $3 \mathrm{~mL}$ distilled water was performed, concluding the smear layer removal procedure.

Using the same protocol, groups with US were prepared. First, the root canals were filled with $2 \mathrm{~mL}$ of tested solution. Then, the tested solution remained in contact with root canal walls for $2 \mathrm{~min}$. Next, US was performed using an ultrasonic device (Nac Plus Ultrasonics - Adiel, Ribeirão Preto, SP, Brazil). The stainlesssteel endodontic tip to a size ET40 (Satelec-Acteon, Mount Laurel, NJ, USA) was inserted $1 \mathrm{~mm}$ short of the working length and activated for $1 \mathrm{~min}$, resulting in the same $3 \mathrm{~min}$ of contact with root canals, as performed in groups with no US. Scale power 3 for endodontics ( $75 \%$ power) was used to promote the ultrasonic activation. After that, irrigation with $3 \mathrm{~mL}$ of distilled water was performed, concluding the smear layer removal procedure.

\section{Scanning Electron Microscopy (SEM)}

All root canals were dried with \#60 size paper points (Tanari, Manaus, AM, Brazil) after procedures of smear layer removal. Two longitudinal grooves were prepared on the external root surface by diamond disc without reaching the canal space. Subsequently, the roots were split into two halves with a hammer and chisel. For each root, the half containing the most visible part of the apex was used for SEM preparation and analysis. The samples were dehydrated in increasing ethanol concentrations up to $100 \%$ and mounted on aluminum stubs. Next, they were coated with gold palladium and examined in a scanning electron microscope (JSM $6460 \mathrm{LV}$; JEOL, Tokyo, Japan) operated at $15 \mathrm{kV}$.

All samples were numbered, and the images were obtained without disclosing the tested group. First, a scan of all samples was made at $30 \mathrm{x}$ of magnification for each group, in order to identify each third. Then, an area of each third of each tooth was randomly selected and magnified at 100x. Each 100x image was scanned, and three areas were magnified at $1000 \mathrm{x}$ in order to perform the capture of images. Therefore, three images of each third were obtained for each tooth, providing 9 images per tooth and 90 images per group $(n=10)$. In the end, each group had 30 images for each third of root canal. 


\section{SEM evaluation}

The effectiveness of tested protocols on smear layer removal was evaluated by the scoring system described by Prado et al.11, where each micrograph was scored using a semi-quantitative analysis with a four step scale as follows: score 1 - no smear layer, with all tubules cleaned and opened; score 2 = few areas covered by smear layer, with most tubules cleaned and open; score 3 = smear layer covering almost all the surface, with few open tubules; and score $4=$ smear layer covering all the surfaces. Two blinded observers performed this evaluation. Figure 1 provides illustration of representative photomicrographs of the scoring system used to analyze the SEM results.

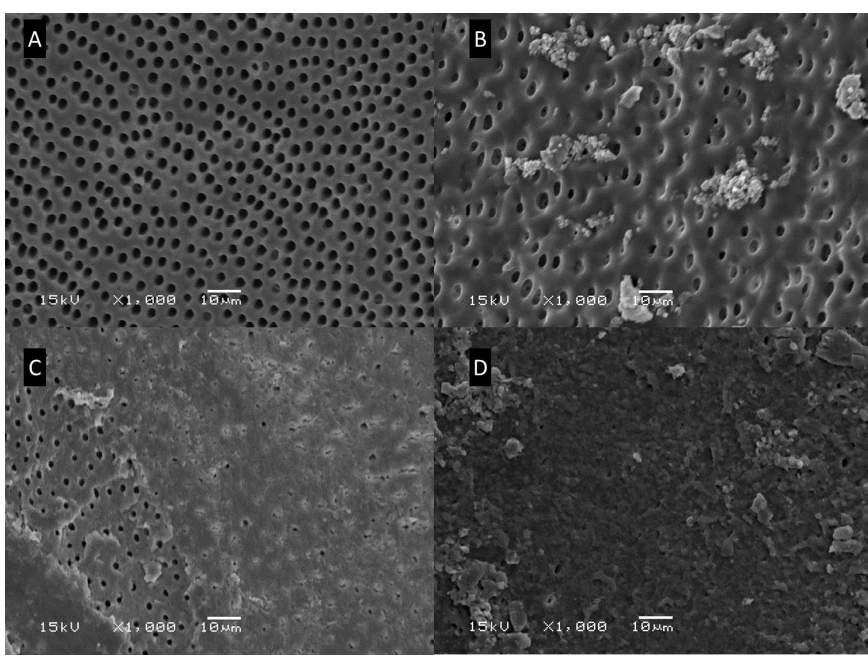

Fig.1. Photomicrographs by SEM of the scoring system used to analyze the effectiveness of each group in smear layer removal. (A) Score 1; (B) Score 2; (C) Score 3; (D) Score 4.

\section{Statistical analysis}

The weighted Kappa coefficient test was performed in order to verify the reliability for the SEM evaluation between the readings of observers. The data were analyzed using the KruskalWallis and Mann-Whitney $U$ tests for intergroup comparisons $(p<0.05)$ as well as the Wilcoxon and Friedman tests for intragroup comparisons $(\mathrm{p}<0.05)$.

\section{Results}

The Kappa test showed good agreement between observers, with values of 0.9 or above. The mean and standard deviation of smear layer scores for each group are in Table 1.

The intergroup analysis revealed that the US did not promote better results to tested substances in the cervical third. In the middle and apical third, groups 17\% EDTA + US and QMix + US were more effective on smear layer removal compared with all other groups, with no statistically significant difference between them $(p<0.05)$, and similar to group 17\% EDTA in the apical third.

Furthermore, the intragroup analysis revealed that groups $17 \%$ EDTA and QMix + US were more effective in the cervical third than in the apical third, being similar to medium third; whereas QMix, $10 \%$ citric acid and $10 \%$ citric acid + US were more effective in the cervical third when compared to medium and apical third $(\mathrm{p}<0.05)$.
Table 1 - Mean and standard deviation of smear layer scores for each group.

\begin{tabular}{lccc}
\hline Group & Cervical & Middle & Apical \\
1. DW & $3.50 \pm 0.52^{\mathrm{A}, \mathrm{a}}$ & $3.50 \pm 0.52^{\mathrm{A}, \mathrm{a}}$ & $3.50 \pm 0.52^{\mathrm{A,a}}$ \\
2. DW+US & $3.45 \pm 0.48^{\mathrm{A}, \mathrm{a}}$ & $3.48 \pm 0.51^{\mathrm{A}, \mathrm{a}}$ & $3.49 \pm 0.50^{\mathrm{A}, \mathrm{a}}$ \\
3.EDTA & $1.70 \pm 0.67^{\mathrm{B}, \mathrm{a}}$ & $2.10 \pm 0.73^{\mathrm{B}, \mathrm{ab}}$ & $2.10 \pm 0.50^{\mathrm{B}, \mathrm{b}}$ \\
4. QMix & $1.40 \pm 0.51^{\mathrm{B}, \mathrm{a}}$ & $2.40 \pm 0.96^{\mathrm{B}, \mathrm{b}}$ & $2.80 \pm 0.78^{\mathrm{A}, \mathrm{b}}$ \\
5. Citric acid & $1.70 \pm 0.48^{\mathrm{B}, \mathrm{a}}$ & $2.50 \pm 0.52^{\mathrm{B}, \mathrm{b}}$ & $2.70 \pm 0.48^{\mathrm{A}, \mathrm{b}}$ \\
6. Phosphoric acid & $3.20 \pm 0.78^{\mathrm{A}, \mathrm{a}}$ & $3.30 \pm 0.67^{\mathrm{A}, \mathrm{a}}$ & $3.30 \pm 0.82^{\mathrm{A}, \mathrm{a}}$ \\
7. EDTA+US & $1.60 \pm 0.51^{\mathrm{B}, \mathrm{a}}$ & $1.50 \pm 0.52^{\mathrm{C}, \mathrm{a}}$ & $2.00 \pm 0.53^{\mathrm{B}, \mathrm{a}}$ \\
8. QMix+US & $1.20 \pm 0.42^{\mathrm{B}, \mathrm{a}}$ & $1.50 \pm 0.52^{\mathrm{C}, \mathrm{ab}}$ & $2.00 \pm 0.61^{\mathrm{B}, \mathrm{b}}$ \\
9. Citric acid+US & $1.90 \pm 0.31^{\mathrm{B}, \mathrm{a}}$ & $2.40 \pm 0.80^{\mathrm{B}, \mathrm{b}}$ & $3.30 \pm 0.82^{\mathrm{A}, \mathrm{b}}$ \\
10. Phosphoric acid+US & $3.30 \pm 0.67^{\mathrm{A}, \mathrm{a}}$ & $3.30 \pm 0.48^{\mathrm{A}, \mathrm{a}}$ & $3.30 \pm 0.67^{\mathrm{A}, \mathrm{a}}$ \\
\hline
\end{tabular}

${ }^{*}$ Different capital letters indicate significant differences between groups. Different smal letters indicate significant differences between root thirds $(p<0.05)$

${ }^{* *} \mathrm{DW}=$ distilled water; US=ultrasonic activation

\section{Discussion}

The action time of auxiliary chemical substances used inside the root canal as final irrigants is variable in the literature. According to a previous study by Prado et al. ${ }^{11}$, 17\% EDTA was used for $30 \mathrm{~s}$. However, this chelating agent used for a short period resulted in low performance in smear layer removal, compared with results obtained by distilled water (control group). This results underscores that $17 \%$ EDTA is ineffective for smear layer removal after $30 \mathrm{~s}$ of contact with root canal walls. Çalt and Serper ${ }^{12}$ found similar results, where the use of chelating agents for 1 min did not result in effective removal of smear layer produced over radicular dentin. The action time of final irrigation protocols tested in the present study was set at 3-min contact with the root canal walls. This time was based on a previous study of Scelza et al. ${ }^{13}$, where the results showed that final irrigation protocols were effective after $3 \mathrm{~min}$ and did not show better results for smear layer removal after increasing the contact time of chemical agents with the root canal walls.

The null hypothesis of present study, that US over four chelating agents would not promote better removal of the smear layer was not confirmed, since the use of US has not improved only the ability of $10 \%$ citric acid and $37 \%$ phosphoric acid to promote smear layer removal in every third of root canal. The use of ultrasonic activation (US) as an auxiliary technique in endodontic therapy has been suggested as a method to increase cleaning and disinfection of the root canal system ${ }^{8,14}$. However, its use has been limited to endodontic irrigants such as $\mathrm{NaOCl}$ and calcium hypochlorite ${ }^{15,16}$. Our goals were to investigate the influence of ultrasonic activation on improvement of four chelating agents in smear layer removal. According to the results of the present study, the use of US with the four tested chelating agents in the cervical third did not improve the smear layer removal capacity compared with groups where US was not used. However, in the middle third, groups $17 \%$ EDTA + US and QMix + US have shown a higher ability to promote smear layer removal compared with all other groups. However, in the apical third, the group 
QMix + US has shown a greater ability to promote smear layer removal when compared with group QMix, where US was not performed. These findings are in accordance with those of with previous studies, which reported that smear layer removal was enhanced with the adjunctive use of ultrasonic irrigation ${ }^{9,10,17}$. The action of ultrasonic devices induces hydrodynamic turbulence in the solution inside the root canal, producing cavitation and bubbles that collide against the walls. These elements increase the temperature and hydrostatic pressure, producing waves to remove the smear layer by continuous irrigation with ultrasonic device ${ }^{18}$.

The higher effectiveness of QMix + US on smear layer removal in the cervical third compared with the apical third may be explained by the higher volume of contact of the tested chelating agents in the cervical third and by the difficulty of effectively reaching the remaining thirds of the root canals. Due that oscillation amplitude is greatest on the tip of the instrument, any interference may significantly affect the apical portion ${ }^{19}$. The current results confirm these concepts, because US has shown less influence on QMix and 10\% citric acid in smear layer removal in the apical portion of the root canals.

The 37\% phosphoric acid did not demonstrate effectiveness in smear layer removal, according to the results of the present study, even with US. The results of groups $37 \%$ phosphoric acid and $37 \%$ phosphoric acid + US were similar to control group (DW), revealing high amounts of smear layer after the tested protocols. The present results disagree with those of a previous study ${ }^{11}$ in which phosphoric acid solution showed excellent results on smear layer removal after a 3-min exposure, even in the apical third. However, the use of high-concentration phosphoric acid is related to dentinal erosion ${ }^{11}$ and may carry a higher risk of cytotoxicity, especially when used in the apical third of the root canal.

The lowest means of smear layer removal were observed in the groups 17\% EDTA + US and QMix + US, even with no statistically significant difference between these groups and group $17 \%$ EDTA, in the cervical and apical thirds. However, $17 \%$ EDTA may promote erosion of peritubular and intertubular dentin, which may compromise the fracture strength of tooth ${ }^{20-22}$. Despite the presence of EDTA in its composition, QMix has not shown the ability to promote dentinal erosion ${ }^{20}$. QMix also comprises chlorhexidine and a detergent (surfactant agent). Chlorhexidine has a broad spectrum of antimicrobial activity ${ }^{23}$, substantivity ${ }^{24}$ and promotes a reduction of dentinal microhardness ${ }^{25}$, while the surfactant agent decreases the surface tension and increases the wettability ${ }^{26}$, increasing the effectiveness in penetrating deeper into the dentinal tubules, thus contributing to decontamination of root canal system. For these reasons and according to current results, the present study suggests that the QMix with US may be a good protocol for final irrigation, reinforcing the findings of Niu et al. ${ }^{27}$, where activation of QMix appears to maximize the smear layer removal, bringing significant benefits to endodontic therapy.

Considering such results, we believe that ultrasonic activation can aid $17 \%$ EDTA and QMix in smear layer removal, contributing in a significant way to the cleaning of root canal system, since better results were found for 17\% EDTA and QMix in the middle third, and for QMix in apical third when ultrasonic activation of these substances was performed. Further studies are required to evaluate the depth of demineralization caused by US with chelating agents and its influence on dentinal adhesion of filling materials in order to optimize these protocols in endodontics.

\section{References}

1. Kakehashi S, Stanley HR, Fitzgerald RJ. The effects of surgical exposures of dental pulps in germ-free and conventional laboratory rats. Oral Surg Oral Med Oral Pathol . 1965 Sep;20:340-9.

2. Teixeira CS, Felippe MC, Felippe WT. The effect of application time of EDTA and $\mathrm{NaOCl}$ on intracanal smear layer removal: an SEM analysis. Int Endod J. 2005 May;38(5):285-90.

3. Wang Z, Shen Y, Haapasalo M. Effect of smear layer against disinfection protocols on Enterococcus faecalis-infected dentin. J Endod. 2013 Nov;39(11):1395-400. doi: 10.1016/j.joen.2013.05.007.

4. Shahravan A, Haghdoost AA, Adl A, Rahimi H, Shadifar F. Effect of smear layer on sealing ability of canal obturation: a systematic review and meta-analysis. J Endod. 2007 Feb;33(2):96-105.

5. Pérez-Heredia M, Ferrer-Luque CM, González-Rodríguez MP, MartínPeinado FJ, González-López S. Decalcifying effect of 15\% EDTA, $15 \%$ citric acid, $5 \%$ phosphoric acid and $2.5 \%$ sodium hypochlorite on root canal dentine. Int Endod J. 2008 May;41(5):418-23. doi: 10.1111/j.1365-2591.2007.01371.x.

6. Stojicic S, Shen Y, Qian W, Johnson B, Haapasalo M. Antibacterial and smear layer removal ability of a novel irrigant, QMiX. Int Endod J. 2012 Apr;45(4):363-71. doi: 10.1111/j.1365-2591.2011.01985.x.

7. George S, Kishen A, Song KP. The role of environmental changes on monospecies biofilm formation on root canal wall by Enterococcus faecalis. J Endod. 2005 Dec;31(12):867-72.

8. van der Sluis LW, Versluis M, Wu MK, Wesselink PR. Passive ultrasonic irrigation of the root canal: a review of the literature. Int Endod J. 2007 Jun;40(6):415-26. Epub 2007 Apr 17.

9. Caron G, Nham K, Bronnec F, Machtou P. Effectiveness of different final irrigant activation protocols on smear layer removal in curved canals. J Endod. 2010 Aug;36(8):1361-6. doi: 10.1016/j.joen.2010.03.037.

10. Blank-Gonçalves LM, Nabeshima CK, Martins GH, Machado ME. Qualitative analysis of the removal of the smear layer in the apical third of curved roots: conventional irrigation versus activation systems. J Endod. 2011 Sep;37(9):1268-71. doi: 10.1016/j.joen.2011.06.009.

11. Prado M, Gusman H, Gomes BP, Simão RA. Scanning electron microscopic investigation of the effectiveness of phosphoric acid in smear layer removal when compared with EDTA and citric acid. $J$ Endod. 2011 Feb;37(2):255-8. doi: 10.1016/j.joen.2010.11.011.

12. Calt $S$, Serper A. Time-dependent effects of EDTA on dentin structures. J Endod. 2002 Jan;28(1):17-9.

13. Scelza MF, Pierro V, Scelza P, Pereira M. Effect of three different time periods of irrigation with EDTA-T, EDTA, and citric acid on smear layer removal. Oral Surg Oral Med Oral Pathol Oral Radiol Endod. 2004 Oct;98(4):499-503

14. Plotino G, Pameijer CH, Grande NM, Somma F. Ultrasonics in endodontics: a review of the literature. J Endod. 2007 Feb;33(2):81-95.

15. Gründling GL, Zechin JG, Jardim WM, de Oliveira SD, de Figueiredo JA. Effect of ultrasonics on Enterococcus faecalis biofilm in a bovine tooth model. J Endod. 2011 Aug;37(8):1128-33. doi: 10.1016/j. joen.2011.05.006.

16. de Almeida AP, Souza MA, Miyagaki DC, Dal Bello Y, Cecchin D, Farina AP. Comparative evaluation of calcium hypochlorite and sodium hypochlorite associated with passive ultrasonic irrigation on antimicrobial activity of a root canal system infected with Enterococcus 
faecalis: an in vitro study. J Endod. 2014 Dec;40(12):1953-7. doi: 10.1016/j.joen.2014.08.025.

17. Rödig T, Döllmann S, Konietschke F, Drebenstedt S, Hülsmann M. Effectiveness of different irrigant agitation techniques on debris and smear layer removal in curved root canals: a scanning electron microscopy study. J Endod. 2010 Dec;36(12):1983-7. doi: 10.1016/j. joen.2010.08.056.

18. Ribeiro EM, Silva-Sousa YT, Souza-Gabriel AE, Sousa-Neto MD, Lorencetti KT, Silva SR. Debris and smear removal in flattened root canals after use of different irrigant agitation protocols. Microsc Res Tech. 2012 Jun;75(6):781-90. doi: 10.1002/jemt.21125.

19. Jensen SA, Walker TL, Hutter JW, Nicoll BK. Comparison of the cleaning efficacy of passive sonic activation and passive ultrasonic activation after hand instrumentation in molar root canals. J Endod. 1999 Nov;25(11):735-8.

20. Saghiri MA, Delvarani A, Mehrvarzfar P, Malganji G, Lotfi M, Dadresanfar $B$, et al. A study of the relation between erosion and microhardness of root canal dentin. Oral Surg Oral Med Oral Pathol Oral Radiol Endod. 2009 Dec;108(6):e29-34. doi: 10.1016/j. tripleo.2009.07.056.

21. Qian W, Shen Y, Haapasalo M. Quantitative analysis of the effect of irrigant solution sequences on dentin erosion. J Endod. 2011 Oct;37(10):1437-41. doi: 10.1016/j.joen.2011.06.005.
22. Aranda-Garcia AJ, Kuga MC, Chavéz-Andrade GM, Kalatzis-Sousa NG, Hungaro Duarte MA, Faria G, et al. Effect of final irrigation protocols on microhardness and erosion of root canal dentin. Microsc Res Tech. 2013 Oct;76(10):1079-83. doi: 10.1002/jemt.22268.

23. Ferraz CC, Gomes BP, Zaia AA, Teixeira FB, Souza-Filho FJ. In vitro assessment of the antimicrobial action and the mechanical ability of chlorhexidine gel as an endodontic irrigant. J Endod. 2001 Jul;27(7):452-5.

24. Böttcher DE, Sehnem NT, Montagner F, Fatturi Parolo CC, Grecca FS. Evaluation of the Effect of Enterococcus faecalis Biofilm on the 2\% Chlorhexidine Substantivity: An In Vitro Study. J Endod. 2015 Aug;41(8):1364-70. doi: 10.1016/j.joen.2015.04.016.

25. Oliveira LD, Carvalho CA, Nunes W, Valera MC, Camargo $\mathrm{CH}$, Jorge $\mathrm{AO}$. Effects of chlorhexidine and sodium hypochlorite on the microhardness of root canal dentin. Oral Surg Oral Med Oral Pathol Oral Radiol Endod. 2007 Oct;104(4):e125-8.

26. Giardino L, Ambu E, Becce C, Rimondini L, Morra M. Surface tension comparison of four common root canal irrigants and two new irrigants containing antibiotic. J Endod. 2006 Nov;32(11):1091-3.

27. Niu LN, Luo XJ, Li GH, Bortoluzzi EA, Mao J, Chen JH, et al. Effects of different sonic activation protocols on debridement efficacy in teeth with single-rooted canals. J Dent. 2014 Aug;42(8):1001-9. doi: 10.1016/j. jdent.2014.05.007. 